\title{
An Ethical Framework to Manage Patient Requests for Medical Marijuana
}

\author{
Michael Redinger, MD, MA, Nicole Fledderman, BS, and Parker Crutchfield, PhD
}

An increasing number of states are legalizing marijuana use for medicinal purposes despite marijuana use remaining criminalized at the federal level and continued Schedule I status by the US Food and Drug Administration. Many of those states in which medical marijuana is legal require physician involvement to facilitate patient access. In addition, physicians may have ethical objections to medical marijuana use or may not believe there is adequate scientific evidence to support its use. The constellation of these factors creates an ethical quandary for physicians when approached by patients for assistance in accessing medical marijuana. This article provides an ethical framework that provides guidance to physicians in managing these patient requests taking into consideration the above ethically relevant factors. (J Am Board Fam Med 2020;33:147-151.)

Keywords: Bioethics, Cannabis, Drug Legislation, Marijuana Use, Medical Ethics, Medical Marijuana

Over the last 2 decades, an increasing number of states and municipalities have legalized marijuana use for medicinal purposes, despite marijuana use remaining criminalized by the federal government and continued Schedule I status by the US Food and Drug Administration (FDA). ${ }^{1-5}$ This legal and regulatory setup has complicated the practice of physicians who receive requests for medical marijuana from their patients, as many statutory processes require some degree of physician participation for patients to access marijuana legally. ${ }^{3-4}$ Controversy over the medical benefits and harms of marijuana and the appropriateness of legalization has created ethical dilemmas for physicians. But there has been insufficient guidance from professional societies, regulatory boards, or medical ethicists. ${ }^{4-5}$ Further, they do not take into consideration that the ethical duties of physicians may vary due to the

This article was externally peer reviewed.

Submitted 20 June 2019; revised 15 August 2019; accepted 15 August 2019.

From the Western Michigan University Homer Stryker M.D. School of Medicine, Kalamazoo, MI.

Funding: none.

Conflict of interest: none declared.

Corresponding author: Michael Redinger, MD, MA, Department of Psychiatry and Department of Medical Ethics, Humanities, and Law, Western Michigan University Homer Stryker M.D. School of Medicine, 1000 Oakland Drive, Kalamazoo, MI 49008 (E-mail: Michael.redinger@med.wmich.edu). degree of physician participation in the process depending on the state of practice, because there is legitimate scientific disagreement about the efficacy, risks, burdens of medical marijuana treatment, or when the physician has a conscientious objection to facilitating patient access to marijuana. This article is intended to provide an ethical framework for physicians who receive legitimate patient requests for assistance in obtaining legal medical marijuana, excluding requests made for the purposes of recreational use or diversion.

\section{Types of Physician Involvement}

Physician involvement in the process of patient access to medical marijuana varies depending on the state. ${ }^{2}$ All physicians should be aware of the legality of medical marijuana in the states in which they practice. If they practice in an area where medical marijuana is legal, there are various ways in which physician involvement may be required. The scope of that participation impacts its ethical nature.

First, physicians should be aware that marijuana remains a Schedule I drug by the FDA. As a result, the "prescribing" of marijuana for medicinal purposes, defined by the FDA as "an order to a patient to consume a controlled substance, as well as an order to a pharmacist to prepare and distribute the 
substance" remains illegal and could result in revocation of Drug Enforcement Administration licensure and criminal charges. ${ }^{2}$ Currently, there are only 3 cannabis-based products with FDA approval-dronabinol, nabilone, and Epidiolex. ${ }^{8}$ Dronabinol (Brand Names: Marinol, Syndros) is FDA approved for adults in the treatment of anorexia associated with weight loss in patients with Acquired Immunodeficiency Syndrome..$^{5-7}$ Dronabinol and nabilone (Brand Name: Cesamet) have FDA approval for adults in the treatment of nausea and vomiting associated with cancer chemotherapy in patients who have failed to respond adequately to conventional antiemetic treatments. ${ }^{5-7}$ Currently, the only cannabidiol product approved by the FDA is a prescription product oil called Epidiolex, which is approved for the treatment of 2 types of epilepsy in children. ${ }^{8-9}$ While cannabidiol not sold as Epidiolex remains a Schedule I controlled substance according to the Drug Enforcement Administration and FDA, the 2018 Farm Act removed hemp-defined as cannabis plants containing less than $0.3 \%$ THC-from the Schedule I Controlled Substances list. ${ }^{8-9}$ Simply put, cannabidiol sourced from hemp products is legal in all 50 states whereas cannabidiol sourced from marijuana plants remains subject to individual state laws. ${ }^{8-9}$ Dronabinol and nabilone consist of a synthetic form of $\delta$-9-THC which is the primary psychoactive cannabinoid found in the Cannabis sativa plant most commonly used for medical marijuana. ${ }^{5,7}$ Cannabidiol contains minimal 8-9-THC and as such does not cause the user to experience the "high" associated with marijuana." This article is not intended to address the legal prescribing of dronabinol, nabilone, or cannabidiol. Rather, it is intended to guide clinicians who are approached by patients for assistance in accessing marijuana under the Schedule I formulation with the intent to use the marijuana for treatment of a medical condition, including but not limited to the indications of FDA approved formulations, and not with the intent to use it for recreational purposes or distribute it illegally.

In states or municipalities where Schedule I marijuana has been legalized for medicinal purposes, physician involvement can be characterized by either "recommending" its use or by "attesting" that patients have a qualifying condition which allows them to access medical marijuana from a legal source. ${ }^{3}$ Physicians may have an ethical objection to recommending medical marijuana but not to attesting to the presence of a patient condition or may have an ethical objection to both or neither. An ethical objection to recommendation of medical marijuana use but not attestation of a qualifying condition may hinge on what the physician perceives to be their degree of involvement, and thus, moral culpability, in a patient's immoral action. As an analogy, a physician may be hesitant to recommend that a patient participate in bull fighting because of a moral objection to the practice out of concern for the welfare of the bull, but may not have an objection to completing an attestation of the matador's health required for his or her participation in the sport. For those who believe attestation of a qualifying condition is a morally neutral act, regardless of what action that attestation will allow the patient to do afterward, then there should be no objection to completing the form. For others, attestation may bear less moral complicity than recommending its use, but this is simply a matter of degree.

Analogously, the distinction between prescribing and attesting can be seen in disability evaluation. Consider the patient who has a qualifying condition for disability but who lacks functional limitations. A physician may be less comfortable recommending a patient obtain disability than attesting to the presence of the qualifying condition. We recommend that physicians be aware of the specific requirements for their participation in their legal jurisdiction and reflect carefully on what degree of participation they find morally objectionable. For simplicity, from this point forward we will refer to either of these actions, recommending or attesting, to "assisting" in the patient's accessing of medical marijuana.

In addition, there are myriad philosophical, cultural, or religious reasons which may predispose a physician to conscientiously object and defer from assisting patients in accessing legal medical marijuana. In the spirit of tolerance, we presume that at least some of these are well founded but recommend careful reflection regardless of final position. Defensible reasons for conscientious objection may include an objection to the use of intoxicating substances or respect for the rule of law. Generally these objections should not be hiding other selfserving interests and they should reflect deeply held and long-standing values. Nor should conscientious objection be used as a pretense for discrimi- 
Table 1. Ethical Requirements of the Physician Depending on Their Assessment of the Scientific Evidence Supporting or Dissuading Medical Marijuana for a Particular Condition and if They Have a Personal Moral Commitment Opposed to Attest or Recommend Medical Marijuana Use

\begin{tabular}{|c|c|c|}
\hline \multicolumn{3}{|c|}{ A Four-Box Approach to a Physician's Ethical Obligations } \\
\hline \multirow{2}{*}{$\begin{array}{l}\text { Willingness to attest/ } \\
\text { recommend }\end{array}$} & \multicolumn{2}{|c|}{ Science } \\
\hline & Benefit & No Benefit \\
\hline \multirow{6}{*}{ Yes } & Box A & Box B \\
\hline & $\begin{array}{l}\text { Analogous to the physician's evidence-based } \\
\text { decision to prescribe any other medication }\end{array}$ & $\begin{array}{l}\text { Analogous to requests for experimental treatments } \\
\text { or homeopathic remedies }\end{array}$ \\
\hline & $\begin{array}{l}\text { Same ethical obligations: obtain informed } \\
\text { consent by educating the patient about } \\
\text { potential risks, benefits, and burdens of }\end{array}$ & $\begin{array}{l}\text { If science is ambiguous, the physician has additional } \\
\text { ethical obligations beyond educating the patient on } \\
\text { same topics required for informed consent }\end{array}$ \\
\hline & - The prescribed treatment & $\begin{array}{l}\text { - Educate the patient about why there is a lack of } \\
\text { evidence which may create increased risk }\end{array}$ \\
\hline & - Declining treatment & $\begin{array}{l}\text { If the harms seem to clearly outweigh the } \\
\text { potential benefit, physician may decline to assist } \\
\text { the patient }\end{array}$ \\
\hline & & - Assistance would be medically inappropriate \\
\hline \multirow{5}{*}{ No } & Box C & Box D \\
\hline & $\begin{array}{l}\text { Ethical obligation to be transparent with } \\
\text { the patient }\end{array}$ & $\begin{array}{l}\text { Ethical obligation to be transparent with the } \\
\text { patient }\end{array}$ \\
\hline & \multirow{3}{*}{$\begin{array}{l}\text { May have an obligation to refer the patient } \\
\text { to a provider who does not have a moral } \\
\text { objection to assisting }\end{array}$} & $\begin{array}{l}\text { Inform the patient of both reasons for decision to } \\
\text { decline assistance }\end{array}$ \\
\hline & & - Institutional/personal objections to assisting \\
\hline & & $\begin{array}{l}\text { - Lack of scientific evidence supporting potential } \\
\text { benefit }\end{array}$ \\
\hline
\end{tabular}

nation against patients who are members of historically disenfranchised groups. Statutory protection for conscientious objection varies in different legal jurisdiction; thus, physicians are encouraged to use legal resources to ensure knowledge of the law in their area. ${ }^{10}$

Likewise, well-intentioned physicians may have legitimate professional differences in interpreting whether the scientific evidence supports a medical benefit to marijuana use or if the risks of marijuana use outweigh the potential benefits for some, if not all, medical conditions, and reflects the considerable discord reflected in many evidence-based reviews. ${ }^{1,3,5-7,11}$ Finally, physicians may practice in settings where institutional policies reflect an ethical objection to medical marijuana, such as religiously affiliated hospitals which may have a blanket policy against physicians recommending any illicit substance. All these considerations have implications for how physicians ought to respond to legal patient requests for medical marijuana. In any of these situations, ethics consultation may be beneficial.

\section{Ethical Framework}

Physicians' level of involvement in assisting their patients in obtaining medical marijuana may fall into 1 of 4 categories based on whether they believe the scientific evidence indicates that medical marijuana will benefit their patients' medical conditions and whether their own personal or institutional ethical commitments limits their willingness to attest or recommend their patients' use of medical marijuana. The intersection of these factors creates different ethical obligations for the physician (Table 1). It may be helpful to imagine working through the framework with the following scenario in mind. A 42-year-old woman presents with noncancer-related back pain that has lasted several years since a motor vehicle accident. It has not responded well to physical therapy or nonsteroidal anti-inflammatory medications and the patient does not want to try opioid analgesics. You practice in a state that permits medical marijuana for chronic pain.

Consider first the scenarios in which a physician neither has a personal moral objection nor works in a practice with institutional policies precluding him or 
Table 2. Summary of Ethically Relevant Best Practices for Physicians Assisting Patients in Accessing Medical Marijuana

\begin{tabular}{|c|c|}
\hline \multicolumn{2}{|c|}{ Summary of Professional Recommendations Regarding Medical Marijuana } \\
\hline Supporting Article or Organization & Recommendations \\
\hline $\begin{array}{l}\text { AMA, National Academy of Sciences' } \\
\text { Institute of Medicine, APA, AAFP, } \\
\text { American College of Physicians }\end{array}$ & More research is needed on therapeutic value of cannabis. \\
\hline $\begin{array}{l}\text { AMA, APA, American Society of } \\
\text { Addiction Medicine }{ }^{15,16}\end{array}$ & Do not currently support the use of medical marijuana. \\
\hline \multirow[t]{10}{*}{$\mathrm{FSMB}^{2}$} & $\begin{array}{l}\text { Patient-physician relationship should be established and in place before making } \\
\text { a recommendation for the patient }\end{array}$ \\
\hline & $\begin{array}{l}\text { A documented, in-person medical evaluation must be obtained before a } \\
\text { recommendation is made. }\end{array}$ \\
\hline & $\begin{array}{l}\text { The physicians should discuss the risks and benefits of marijuana use, and the } \\
\text { patient should be advised of the variability and lack of standardization of } \\
\text { marijuana preparations. }\end{array}$ \\
\hline & $\begin{array}{l}\text { A written treatment agreement should include a review of other measures } \\
\text { attempted to ease the patient's symptoms and a specific duration for the } \\
\text { authorization to obtain marijuana for a period no longer than } 12 \text { months. }\end{array}$ \\
\hline & $\begin{array}{l}\text { Recommending marijuana for certain conditions is at the discretion of the } \\
\text { physician but should be in accordance with the current standards of practice } \\
\text { and in compliance with state laws. }\end{array}$ \\
\hline & $\begin{array}{l}\text { The physician should regularly assess the patient's response to the use of } \\
\text { marijuana and overall health and level of function. This assessment should } \\
\text { include the efficacy of treatment, goals of treatment and progress toward } \\
\text { achieving these goals. }\end{array}$ \\
\hline & $\begin{array}{l}\text { Physician should consult or refer patients to pain management, psychiatric, } \\
\text { addiction, or mental health specialist as needed. }\end{array}$ \\
\hline & Physician should keep accurate and complete medical records throughout the process. \\
\hline & $\begin{array}{l}\text { Physicians who recommend marijuana should not be associated in any way with } \\
\text { a dispensary or cultivation center. }\end{array}$ \\
\hline & $\begin{array}{l}\text { Physicians should abstain of the use of marijuana (medical and recreational) } \\
\text { while actively engaged in the practice of medicine. }\end{array}$ \\
\hline
\end{tabular}

AAFP, American Academy of Family Physicians; AMA, American Medical Association; APA, American Psychiatric Association; FSMB, Federation of State Medical Boards.

her from assisting a patient in accessing medical marijuana. One category (Box A) represents the situations in which the physician believes there to be clear scientific evidence that medical marijuana has likely benefits which outweigh the potential harms. This first scenario can be considered analogous to the physician's evidence-based decision to prescribe any other medication. Consequently, physicians have the same ethical obligations: they are obligated to obtain a robustly informed consent by educating a patient about the potential risks, benefits, and burdens of the prescribed treatment, of other treatment options, and of declining treatment. An established existing relationship with a patient is more likely to facilitate an ethically strong informed consent conversation. As such, physicians who may become known in their community for being willing to assist patients in accessing medical marijuana may need to be cautious in acceding to requests from new patients.
Contrast scenario A with those scenarios in which the physician does not have a moral objection to assisting a patient in accessing medical marijuana but believes that the science has not clearly shown that medical marijuana will benefit/improve the patient's medical condition (Box B). This may be the same physician as in the previous scenario but with a different patient presenting with another medical condition for which there is less or no medical evidence in favor of medical marijuana use. This scenario is analogous to requests for experimental treatments or homeopathic remedies. In ambiguous situations where the science is not clear, the physician's ethical obligation is to extensively educate the patient not only about the potential risks, benefits, and burdens of the treatment, but also to educate the patient about why there is a lack of evidence which may create increased risk, such as due to the lack of a strong regulatory process to ensure safety. In those situations 
in which the harms seem to clearly outweigh the potential benefit, the physician may decline to assist the patient, not out of moral objection, but because marijuana would be medically inappropriate. For example, if a patient with a prior history of marijuanainduced psychosis presents requesting assistance in accessing medical marijuana, then assisting the patient in obtaining marijuana is contraindicated and therefore medically inappropriate.

Next consider the scenarios in which the physician, or the institution in which an individual practices, has ethical objections to assisting a patient in accessing medical marijuana regardless of whether the individual believes there is evidence indicating the benefit of medical marijuana (Boxes C and D). In both of these scenarios, we argue that the physician has an ethical obligation to be transparent with the patient regarding the nature of her refusal to assist the patient. There is a lack of consensus in medical ethics about whether conscientious objection is ever morally permissible or, if invoked, whether the physician has an ethical obligation to refer the patient to a provider who does not share the same moral objection to assisting. ${ }^{12-14}$ A physician may be more likely to have an obligation to refer if the physician believes the scientific evidence clearly supports the use of marijuana for the patient's condition. (Box C). Finally, if the physician or their institutional policy is ethically opposed to assisting the patient but the physician also believes the scientific evidence supporting medical marijuana use is dubious for the patient's condition (Box D), we believe that the physician ought to inform the patient of both reasons for their decision to decline to assist the patient. Transparency with patients regarding both reasons to decline assistance facilitates full honesty with the patient and may minimize suspicion on the part of the patient that the physician is not acting in the patient's best interest.

\section{Conclusion}

We recommend that physicians uncertain about their ethical obligations to patients requesting legal medical marijuana first assess their own individual beliefs about the ethical appropriateness of assisting patient access. Discussion with their hospital's clinical ethicist or ethics committee may be helpful. Second, if the physician is willing to assist patients in accessing medical marijuana, that decision must be informed by knowledge of the medical science demonstrating its effectiveness, or the lack thereof, for the conditions for which assistance is being sought. This is the standard for competency for any potential treatment. Finally, for those willing to assist patients in accessing medical marijuana, we also support previously recommended, ethically relevant best practices (Table 2).

To see this article online, please go to: http://jabfm.org/content/ 33/1/147.full.

\section{References}

1. Belendiuk KA, Baldini LL, Bonn-Miller MO. Narrative review of the safety and efficacy of marijuana for the treatment of commonly state-approved medical and psychiatric disorders. Addict Sci Clin Pract 2015;10:10.

2. Chaudhry HJ, Hengerer AS, Snyder GB. Medical board expectations for physicians recommending marijuana. JAMA 2016;316:577.

3. Gregorio J. Physicians, medical marijuana, and the law. Virtual Mentor 2014;16:732-8.

4. Huff C. Medical marijuana: the challenge for physicians. Med Econ 2016;93:61-5.

5. National Academies of Sciences, Engineering, and Medicine. The health effects of cannabis and cannabinoids: the current state of evidence and recommendations for research. Washington, DC: The National Academies Press; 2017.

6. Gloss DS, Maa EH. Medical marijuana: Between a plant and a hard place. Neurol Clin Pract 2015;5: 281-4.

7. Schrot RJ, Hubbard JR. Cannabinoids: medical implications. Ann Med 2016;48:128-41.

8. Corroon J, Kight R. Regulatory status of cannabidiol in the United States: a perspective. Cannabis Cannabinoid Res 2018;3:190-4.

9. Pyne L. Is CBD oil legal? A 2019 state by state legal. CBD Central. Available from: https://www.cbdcentral. com/is-cbd-legal/. Published 2019. Accessed June 14, 2019.

10. Pope T. Legal briefing: conscience clauses and conscientious refusal. J Clin Ethics 2010;21:163-76.

11. Medical uses of cannabinoids. In: DynaMed [database online]. EBSCO Information Services. Updated January 11, 2017. Available from: https://www. dynamed.com/topics/dmp AN T901291/Medicaluses-of-cannabinoids. Accessed June 12, 2017.

12. Savulescu J. Conscientious objection in medicine. BMJ 2006;332:294-7.

13. Wicclair M. Conscientious objection in medicine. Bioethics 2000;14:205-27.

14. Magelssen M. When should conscientious objection be accepted? J Med Ethics 2011;38:18-21.

15. Gordon L. Ethical considerations for psychiatry in the broadening scope of medical marijuana therapy. Ethics Biol Eng Med 2011;2:33-43.

16. Kleber HD, DuPont RL. Physicians and medical marijuana. Am J Psychiatry 2012;169:564-8. 